\title{
SEISMIC DESIGN OF MASONRY BUILDINGS SOME GAPS IN STRUCTURAL EUROCODES AND THEIR CORRECTION BY CODES CR 6 -2013 AND P 100-1/2013
}

\author{
Radu PETROVICI - Professor, PhD, University of Architecture and Urbanism "I. Mincu" Bucureşti, \\ e-mail r.petrovici@uauim.ro
}

\begin{abstract}
Experience of designing buildings with structural masonry walls and masonry nonstructural elements using Codes CR 6-2006 [15a] and P 100-1/2006 [16a], that were developed based on design principles and rules of Eurocodes adopted in Romania SR EN 1996-1-1[13] and SR EN 1998-1[14], revealed the need of some additions and corrections of texts.

These interventions made by developing Codes CR 6 -2013[15] and P 100-1/2013[16], which we can characterize synthetically as follows:

- Are aligned with the Structural Eurocodes principles but correcting some identified deficiencies.

- $\quad$ Resume some previous provisions of national regulations that lack in Eurocodes

- Introduce the results of recent theoretical and experimental research

- Provide practical application rules, simple and explicit, accompanied by "Commentary" and "Design examples"

The communication exposes and justifies synthetically the following new approaches introduced in the 2013 editions of the two regulations:

I. Modification of the methodology for the partial safety factors $\left(\gamma_{M}\right)$ and for establishing the minimum necessary strength values of masonry.

II. Additions and explanations of the design rules for unreinforced and confined masonry subjected to combined axial compression and flexure and to shear loading.
\end{abstract}

Keywords: Eurocode, partial safety factors $\gamma \mathrm{M}$, confined masonry, shear force

\section{Introduction}

The main European standards SR EN (Structural Eurocodes) adopted in Romania which have provisions on the design of structural and nonstructural masonry construction elements and the respective fields for utilization are:

\section{SR EN 1996-1-1: 2006 Design of masonry structures [13]}

The standard does not refer to the special requirements for seismic design situation. SR EN 1998-1 give requirements that complements and are compatible with SR EN 1996-1-1.

\section{SR EN 1998-1: 2004 Design of structures for earthquake resistance.(Chapter 9) [14]}

The standard state that the design of masonry buildings shall be made according to SR EN 19961-1, the rules of SR EN 1998-1 being in addition to those from SR EN 1996-1-1.

An obvious divergence results from the explanations given above for each of these standards: SR EN 1998-1 provides verification of earthquake resistance of masonry buildings with a technical regulation that states that it has no rules for seismic design.

Researchers from several countries ascertained this contradictory situation and it was the subject of a major program of tests with international participation - ESECMaSE [1]. Based on these studies, at the meeting of CEN / TC 250 in June 2010 Germany proposed to amend the current approach for calculating shear according the EC6. The proposed change is major and the experts decided that it shall not be applied before the revision of standard in 2015. Only one amendment 
was introduced that allows countries to partially consider these proposals in the National Annexes (limiting shear strength in terms of "force" and not only in terms of "effort" as today) [3].

This initial contradiction, together with some inconsistencies or insufficient explanations found in the provisions of the mentioned Eurocodes have led to the need to develop national Codes (CR) aligned with the general principles of the Eurocodes SR EN 1996-1-1 and SR EN 1998-1. As a first practical measure, the Codes CR 6-2006 and P 100-1/2006 introduced provisions for the unitary design of masonry building to persistent and seismic design situations.

Given the progress made worldwide in earthquake engineering, given the seismic hazard specific to Romania, and given theoretical and practical knowledge of our engineers in designing masonry structures and nonstructural elements, it appeared appropriate to revise and update the 2006 edition of the national codes. It is worth mentioning that within the 2006 edition of design codes P 100-1 and CR 6 were identified several gaps in the texts and questionable provisions as those related to the design and calculation of shear strength of confined masonry.(see the Eurocodes EC 6 and EC 8).

At the same time, we considered appropriate to introduce in National Codes new provisions arising from research conducted in recent years worldwide. We also updated reference documents, eliminating those withdraw between 2006 and 2013 (in particular, old STAS) and we introduced new regulations. In this context, today in Romania are in force the following Codes related to masonry works:

CR 6 - 2013 Code for Design of Masonry Structures.

P 100 -1/2013 Code for Seismic Design - Part I- Design provisions for buildings

$\checkmark$ Chapter 8 Special provisions for masonry structures

$\checkmark$ Chapter 10 Special provisions for masonry non-structural parts.

NE 036-2014 Code of Practice for the execution and supervising the execution of masonry works

Other EU countries practice the policies of drawn up and use of national codes for design of buildings, in parallel to structural Eurocodes. The compulsory regulation in force in Italy is NTC 2009 [2]. Regarding the use of Eurocodes, this regulation provides that they can be used, as other recognized technical documents, to solve particular situations not treated in [2].

In 2013 editions of national codes CR 6 and P 100-1 we have introduced many new provisions for the design of masonry work intended to eliminate the deficiencies of the previous edition and thereby improve the seismic safety of masonry structures.

\section{Modifying the methodology for determining:}

1. Partial safety factors for material properties $\left(\gamma_{M}\right)$

2. Minimum required values of the characteristic strength of masonry (in compression, in shear and in flexure) for seismic design situation.

\subsection{Establishing the partial safety factor for material properties $\gamma_{M}$}

According to the Standards SR EN 1998-1 and SR EN 1996-1-1, $\gamma_{M}$ values will be given in the National Annex of each country, with the following recommendations:

A. For the design of masonry structural elements in the persistent design situation, $\gamma_{M}$ values will be determined by next criteria:

1. Classes of site control during execution of masonry works.

2. Control of manufacture of components materials (masonry units and mortar). 
Annex A of SR EN 1996-1-1 regarding the methodology and the criteria of professional qualification of the personnel employed for the execution, for supervision and for the inspection of the works, has vague provisions that could create confusion in the practical application.

B. For seismic design situation, $\gamma_{M}$ should be $2 / 3$ of the recommended value for persistent design situation, but not less than 1.5. This condition leads to lower values than those used in Romanian practice and, therefore it was not taken in the Codes P 100-1/2013 and CR 6 -2013.

C. For non-structural elements, in both design situations, the two Eurocodes give the same values as those assigned to structural elements.

For more objective choice of $\gamma_{M}$ values used for calculating the structural members, the Code CR $6-2013$ established that they be related to the methodology of execution control, given in the Code NE 036-2014, depending on the class of importance - exposure and the seismic zone $\left(\boldsymbol{a}_{\boldsymbol{g}}\right)$. The three categories of control (low, normal, special) are detailed in the Code NE 036-2014, differentiated by their content, the frequency with which they are made and the verification objectives. The Code P 100-1/2013 also reduced the $\gamma_{M}$ values compared to the 2006 edition since the probability of occurrence of design ground acceleration was changed by switching "mean recurrence interval" from MRI $=100$ years to MRI $=225$ years. Thus, the imposed uniform increasing of ground seismic acceleration with $25 \%$ over whole territory has been compensated partly, for the current buildings, by reducing the factor $\gamma_{M}=2.2$ in 2006 to $\gamma_{M}=$ 1.9 in the Code CR 6-2013.

For non-structural elements, the Code P 100-1/2013, Chapter 10, set $\gamma_{M}$ values as follows:

- For the persistent design situation, same values as for structural elements.

- For the seismic design situation, for both limit states (ULS and SLS), different values are stated for non-structural parts of building $(\mathrm{A} 1 \mathrm{z} \div \mathrm{A} 3 \mathrm{z})$ as defined by the Code $P$ 100-1/2013 Chapter 10. For example, at ULS, for exterior infill walls (A1z) we have $\gamma_{M}=1.9$, and $\gamma_{M}=1.5$ for partitions (A3z)

Table 1

Values $\gamma_{M}$ : Persistent design situation/Seismic design situation

\begin{tabular}{|c|c|c|c|c|}
\hline \multirow{3}{*}{$\begin{array}{c}\text { Category of } \\
\text { Units }\end{array}$} & Mortar & \multicolumn{3}{|c|}{ Type of site control } \\
\cline { 2 - 5 } & Reduced & Normal & Special \\
\hline \multirow{5}{*}{ Category I } & $\begin{array}{c}\text { Prescribed (G) } \\
\text { Site-made }\end{array}$ & $2.7 / 2.4$ & $2.5 / 2.2$ & $2.2 / 1.9$ \\
\cline { 2 - 5 } & $\begin{array}{c}\text { Prescribed (G) } \\
\text { Factory made mortar } \\
\text { Semi-finished factory mortar }\end{array}$ & $2.5 / 2.2$ & $2.2 / 1.9$ & $2.0 / 1.8$ \\
\cline { 2 - 5 } & Designed mortar (T) and (G) & --- & $2.0 / 1.8$ & 1.8 \\
\hline \multirow{3}{*}{ Category II } & $\begin{array}{c}\text { Prescribed (G) } \\
\text { Site-made }\end{array}$ & $3.0 / 2.7$ & $2.8 / 2.5$ & $2.5 / 2.2$ \\
\cline { 2 - 5 } & $\begin{array}{c}\text { Prescribed (G) } \\
\text { Factory made mortar }\end{array}$ & $2.7 / 2.4$ & $2.5 / 2.2$ & $2.2 / 2.0$ \\
\hline Semi-finished factory mortar
\end{tabular}

(G) $\rightarrow$ General-purpose masonry mortar

$(\mathrm{T}) \rightarrow$ Thin-layer masonry mortar

\subsection{Minimum required values of the characteristic strength of masonry}

Structural Eurocodes EC 6 and EC 8 and National structural codes have different approaches to defining minimum required values of design strength of masonry. SR EN 1996-1-1 did not set minimum values of design strength of masonry units. For mortar, a minimum compressive strength is required only for reinforced/confined masonry in order to protect reinforcements. The 
SR EN 1998-1 provides, in the National Annex, only the minimum necessary strength in compression of units. For mortars, the minimum required values are different for unreinforced, reinforced, and confined masonry. In Italy, the standard UNI EN 998-2, state that the mortars prepared on site does not meet all requirements, but gives no restrictions for use.

The Romanian Codes P100-1/2013 and CR 6 -2013 adopted an approach which is conceptual different from that of the Eurocodes: the use of masonry with minimum characteristic resistance values for the main types of simple mechanical actions. This approach is based upon the fact that masonry resistances do not depend only on the components resistances but they are also functions of the manner in which the units are bonded and the type of component materials (Clay, Autoclaved Aerated Concrete). For example, the compression strength of masonry calculated with relations from Code CR 6 -2013 (par. 4.1.1.1.) for given values of compression strengths of the components vary rather widely depending on specified parameters, as shown in [4] - see figure 1

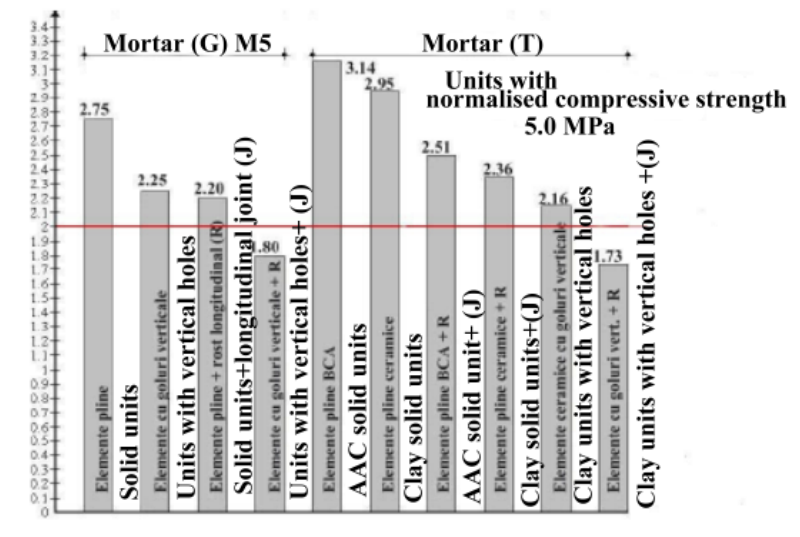

Fig.1 - Variability of the compression strength of masonry depending on units' materials and masonry bond

Hence, the definition of the minimum required compression resistance of masonry only by the minimum resistances of components, as proposed in SR EN 1998-1, is not sufficient.

In the Code P 100-1 / 2013 were established the minimum necessary characteristic strength of masonry under axial and parallel to the bed joints compression and under shear forces. These values are differentiated by: the ground seismic acceleration $\left(\mathrm{a}_{\mathrm{g}}\right)$, the building number of stories $\left(\mathrm{n}_{\text {niv }}\right)$ and the type of masonry units.

For masonry with mortar prepared on site, the Code introduced restrictive measures by using higher safety coefficients, and by limiting their use only for buildings of low importance classes in areas with weak / moderate seismic acceleration $\left(\mathrm{a}_{\mathrm{g}} \leq 0.15 \mathrm{~g}\right)$

The designer in various combinations can choose the masonry units and mortars strengths, required for achieving the masonry resistance values imposed by the Code P 100-1/2013. It is thus possible to choose the best solution in terms of material costs.

Table 2

Minimum required characteristic strength values in compression normal to the bed joints for buildings of III $\div$ IV importance categories $\left(f_{k}\right.$ in $\left.\mathrm{N} / \mathbf{m m}^{2}\right)$

\begin{tabular}{|c|c|c|c|}
\hline \multirow{2}{*}{$\begin{array}{c}\text { Number of storeys } \\
\mathrm{n}_{\text {niv }}\end{array}$} & \multicolumn{3}{|c|}{ Design ground acceleration $a_{g}$} \\
\cline { 2 - 4 } & $0.10 \mathrm{~g} \& 0.15 \mathrm{~g}$ & $0.20 \mathrm{~g} \& 0.25 \mathrm{~g}$ & $0.30 \mathrm{~g} \div 0.40 \mathrm{~g}$ \\
\hline $1(\mathrm{GF})$ & 1.70 & 2.15 & 3.00 \\
\hline $2(\mathrm{GF}+1 \mathrm{~S})$ & 1.85 & 2.30 & 3.15 \\
\hline $3(\mathrm{GF}+2 \mathrm{~S})$ & 2.00 & 2.50 & 3.25 \\
\hline $4(\mathrm{GF}+3 \mathrm{~S})$ & 2.50 & 3.00 & 4.00 \\
\hline $5(\mathrm{GF}+4 \mathrm{~S})$ & 2.70 & Provisions of par.8.3.2.2 (7) applied \\
\hline
\end{tabular}


3. Amendments and clarifications of principles and design rules for unreinforced and confined masonry

\subsection{A method for calculating the ultimate bending moment (MRd) of confined masonry walls subjected to bending and axial loading.}

The standard SR EN 1996-1-1, describe the behavior of masonry walls under eccentric compression (bending \& axial force) acting in their median plane, by an analytical model based on the following hypothesis:

The value of the ultimate moment is calculated considering only the strength of masonry and neglecting the contribution of compressed reinforcement in confining vertical elements.

These assumptions are not realistic, the analytical results being often in contradiction with test values. Therefore it is not recommended that this procedure be used in the design of masonry structures.

The Romanian Code CR 6 -2013 which is mandatory for the design of new masonry buildings, has adopted the following more realistic assumptions for the calculation of the ultimate bending moment $\left(\boldsymbol{M}_{\boldsymbol{R} \boldsymbol{d}}\right)$ associated with a given value of axial load $\left(N_{d}\right)$.

\section{Are neglected.}

- The concrete tensile strength of the confining column at the tension wall edge.

- Tensile strength of the horizontal masonry mortar joints;

- The concrete and the reinforcement of intermediary confining elements (if any);

- The compressive strength of the concrete in the compressed vertical confining element if the masonry units are of group 2 (see table 8.1 of Code P 100-1/2013).

\section{Are taken into account}

- The contribution of vertical confining elements:

- $\quad$ The compressive strength of the concrete in the compressed vertical confining element if the masonry unit are of group 1,

- The reinforcements in both confining vertical elements .

To calculate the ultimate moment $\left(\boldsymbol{M}_{\boldsymbol{R} \boldsymbol{d}}\right)$ compression stresses are deemed to be uniformly distributed, with the value $f_{d}$, over a fraction, $\lambda=0.85 l_{c}$, of the compression zone $\left(l_{c}\right)$.

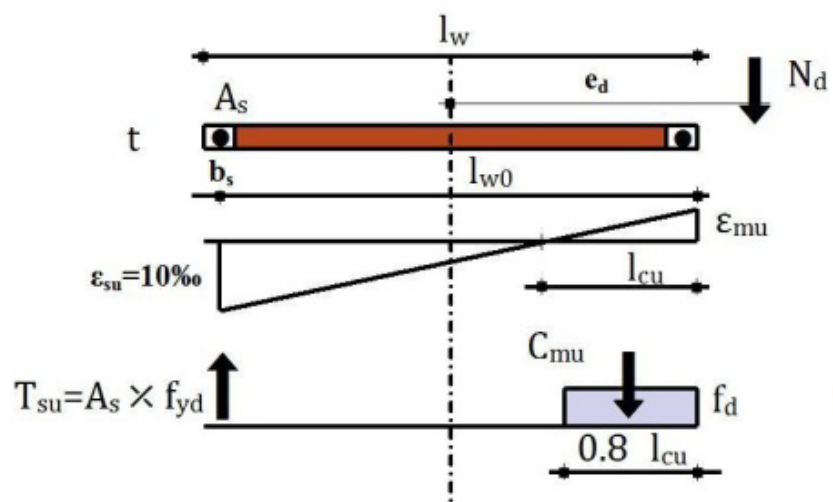

(a)

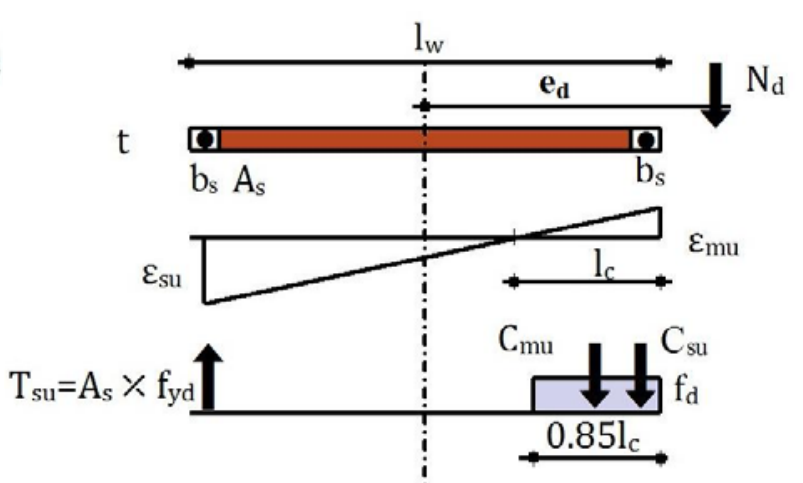

(b) 


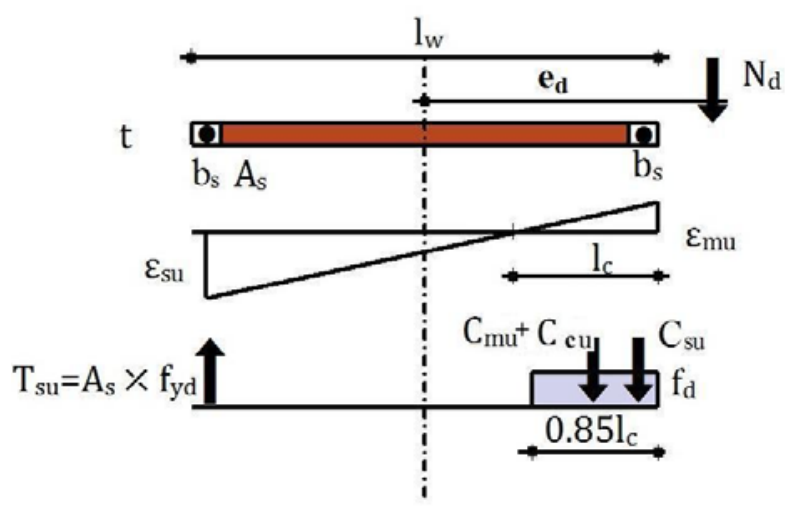

(c)

Fig. 2 - Strain profile and interior forces in the design hypotheses: from SR EN 1996-1-1 (a) and from the Code CR 6 -2013 (b) with group 2 units (c) with group 1 units

The dimensionless values $m_{R d}=\frac{M_{R d}}{\bar{M}_{d}}$ were obtained with the hypothesis from SR EN 1996-1-1 (for both group of units) and with the hypothesis from Code CR 6 -2013 differentiated for the two groups of masonry units of as is shown in figure 2 .

The definitions used are the followings:

- $s_{d}=\frac{\sigma_{d}}{f_{d}}$ is the relative intensity of compression stress (actual compression stress in comparison with the design strength)

- $\quad \bar{M}_{d}=\frac{t \times l_{w}^{2}}{6} \times f_{d}$. is so called "ideal bending moment" (the bending moment of a rectangular section made from a material with the same resistance at compression and at tension); $f_{d}$ is the compression design strength, normal to the bed face.

In diagrams from figure 3 the reinforcement of the confining elements was taken with the values $\mu_{s}=0.00, \mu_{s}=0.05$ and $\mu_{s}=0.10$.

This model is applicable for confined masonry walls, with or without bed joint reinforcement, and built with all types of masonry units.

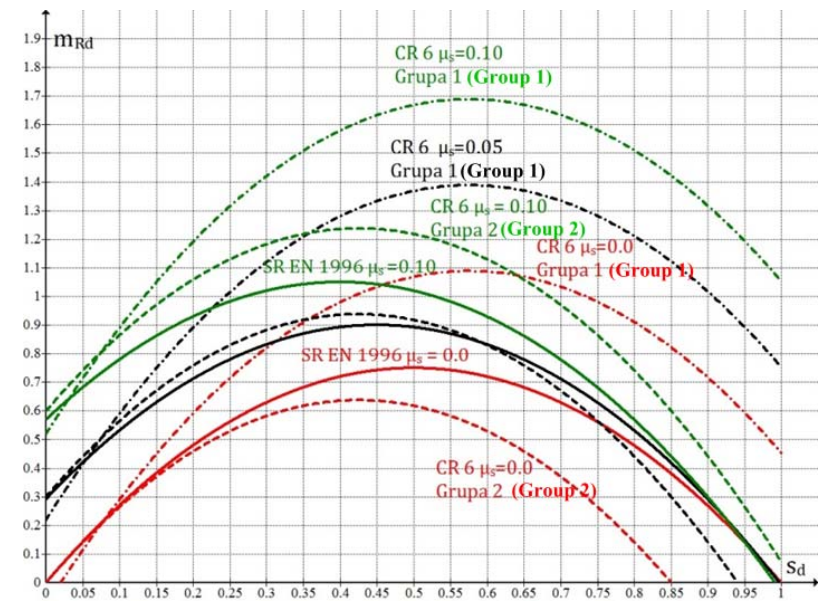

Fig. 3 - Interaction diagrams $\left(\mathrm{m}_{\mathrm{Rd}}-\mathrm{S}_{\mathrm{d}}\right)$ for confined masonry walls according [8] (for units "groups" see table 8.1 in the Code P 100-1/2013)

The examination of the curves $m_{R d}$ from Figure 3 shows two important conclusions:

- The model proposed by SR EN 1996-1-1, underestimate the values of the ultimate moments in comparison with those obtained with the model proposed by national code CR 6 -2013. 
- The use of elements of group 1 provides the greatest values of the ultimate moments for a given axial force as has been show, also, in [4] .

\subsection{Shear strength of masonry shear walls}

The Standard SR EN 1996-1-1 furnish the following definition for shear walls: a wall to resist lateral forces in its plane. Supplemental requirements of this standard, for seismic design situation, are given in SR EN 1998-1. However the analysis of both standards showed that the procedure adopted for calculating the shear strength of masonry walls does not correspond totally to their real behavior to seismic action. The justifications of these statements are the following:

A. The shear strength of masonry walls is calculated only for the mechanism of failure by sliding in horizontal joints.

For an unreinforced masonry wall, the shear strength is the result of the adhesion of the mortar to masonry units and of the dry friction between masonry units on the compressed zone of the wall (Coulomb's law). The fact is that the verification proposed by SR EN 1996-1-1 is rigorously valid only for static forces, which do not modify their sense of action (e.g. lateral thrust of an arc). On the contrary, this scheme is not applicable to seismic action because the alternating sense of bending moment can produce at the ends of the wall a significant reduction, or even losing entirely the adhesion between mortar and masonry units. This severely reduces the shear strength of the wall that will depend only on friction. This observation is found in several books and papers from technical literature as for example in [5] and [6]. Also should be mentioned that, as a supplemental protection, the European standard state that the resistance of any horizontal reinforcement in bed joints, will be neglected in calculations.

B. The failure mechanism triggered by diagonally inclined cracks or "X" shaped cracks (Figure 4b) is completely ignored by Eurocodes although it is most common in seismic design situation.

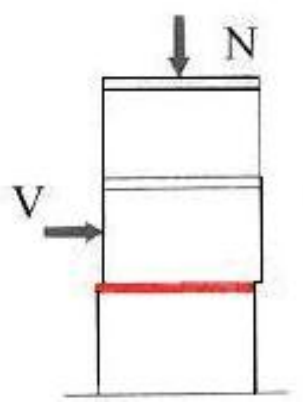

(a)

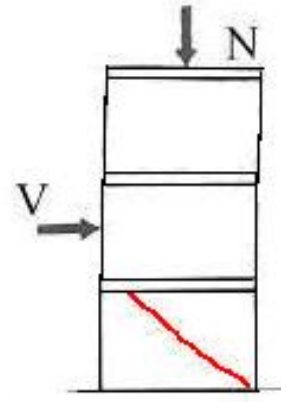

(b)

Fig. 4 - Failure mechanisms of the shear walls

(a) Failure by sliding in horizontal bed (b) Failure upon inclined (diagonal) sections

\subsubsection{Shear strength of unreinforced masonry walls}

For both design situations, the shear strength of a wall is the lowest value resulting from the two failure mechanisms shown in Figure 5.

In order to consider the particularities of failure by sliding in horizontal bed signaled above, the Code CR 6 -2013 gives distinct calculation procedures for the persistent design situation and for the seismic one.

\subsubsection{Failure by sliding in horizontal bed}

The book [9] shown that this failure mechanism is usual in the case of masonry built with strong units and poor quality mortar. 
A. The resistance to shear forces from persistent design situation.

The provisions of SR EN 1996-1-1 are used for this failure mechanism, based on the friction theory and considering the linear distribution of compression stresses (figure 5).

Static force

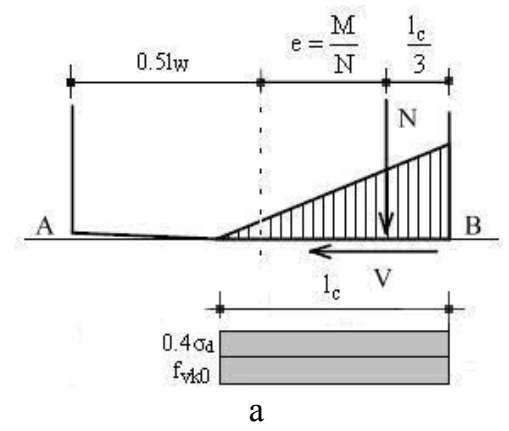

Earthquake force

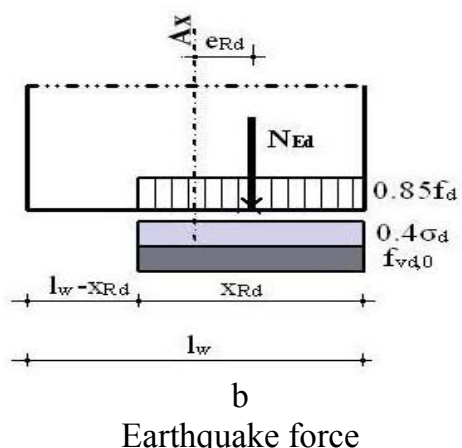

Earthquake force

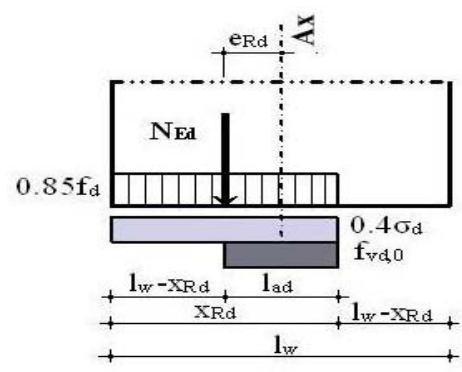

c
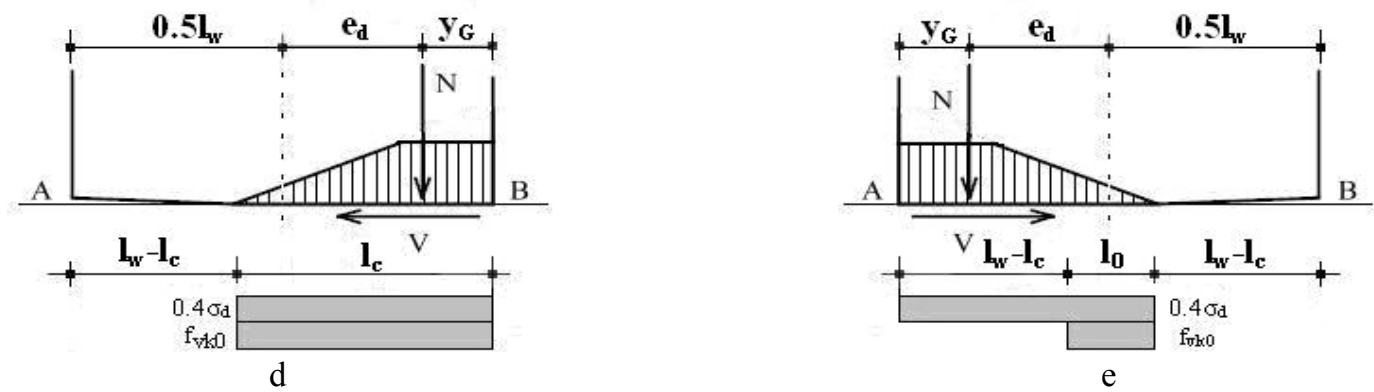

Fig. 5 - Equilibrium of the wall shear stress for:

Persistent (static) loads (a) - SR EN 1996-1-1 Seismic loads (b) and (c) - CR 6 -2013

(d),(e) Seismic loads with elasto-plastic "stress-strain" relationship

The shear strength given by (1) is take constant over the compressed zone of the wall $\left(l_{c}\right)$

$$
f_{v d, l}=\frac{f_{v k, 0}}{\gamma_{M}}+0.4 \sigma_{d}
$$

\section{$B$. The resistance to shear forces from seismic design situation.}

In the case of seismic loading (Figures $5 \mathrm{~b}$ and $5 \mathrm{c}$ ) after reversing the earthquake action, on the area that was cracked in the previous cycle $\left(l_{w}-l_{c}\right)$, the mortar adherence $\left(f_{v d 0}\right)$ was broken and therefore, in this area, the shear strength is achieved only by friction $\left(0.4 \sigma_{d}\right)$. Consequently, the seismic force producing failure by sliding shall be calculated with the relation:

$$
V_{R d, l}=\left(\frac{f_{v k 0}}{\gamma_{M}} \times \frac{l_{a d}}{l_{c}}+0.4 \sigma_{d}\right) \times t l_{c}
$$

\subsubsection{Shear failure by diagonal cracks}

The design of masonry structural walls for this failure mechanism has existed in prior technical regulations from Romania (P2-85 and STAS 10109, now withdrawn).

At present, for the calculation of inclined/diagonal stress, the Code CR $6-2013$ provides the use of empirical relations deduced in the frame of recent European tests campaign [1]:

$$
\begin{aligned}
f_{v k, i} & =0.22 f_{b t} \sqrt{1+5 \frac{\sigma_{0 d}}{f_{b t}}} \text { (Clay units) } \\
f_{v k, i} & =0.10 f_{b t} \sqrt{1+16 \frac{\sigma_{0 d}}{f_{b t}}} \text { (AAC units) }
\end{aligned}
$$


Where:

$f_{b t}$ characteristic tensile strength of masonry;

$\sigma_{0 d}$ the design value of compression stress on the section considered.

Both relations may used for brickwork built with mortar for general purpose $(\mathrm{G})$ or with mortar for thin joints $(\mathrm{T})$, with all joints filled with mortar

Finally, the design shear resistance to failure by diagonal cracks of unreinforced masonry walls will be calculated with the relationship $V_{R d, i}=\frac{A_{w}}{b} f_{v d, i}$ where $b$ is the form factor of the wall.

\subsubsection{Shear strength of confined masonry walls}

For confined masonry structural walls, the design strength against failure by sliding in horizontal bed, $\boldsymbol{V}_{\boldsymbol{R} \boldsymbol{d}}$, will be calculated by adding the following values:

a. The design resistance at sliding into horizontal bed of unreinforced masonry panel

b. The design shear resistance of concrete $\left(V_{R s c}\right)$ and of reinforcement $\left(V_{R d 2}\right)$ in compressed vertical confining element.

To obtain closer results to the real behavior of confined masonry walls to shear action, in the calculation model of Code CR 6 -2013 we have introduced two additional effects:

I. The first item added, was the effect of interaction between the masonry panel and the reinforced concrete confining elements. This interaction generates internal compressive forces on both directions of the panel (vertical and horizontal).

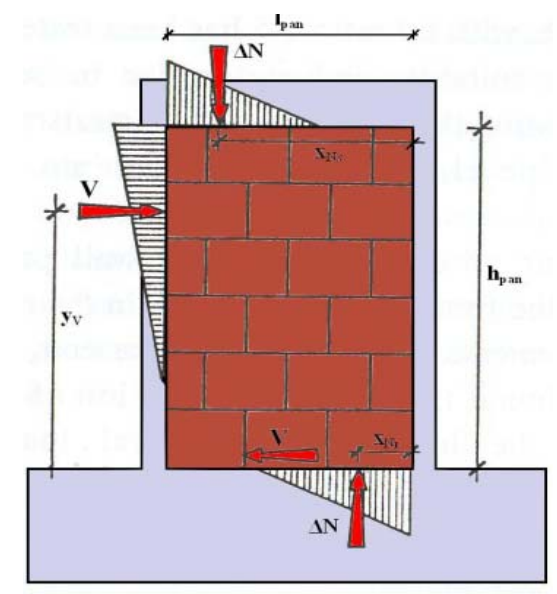

Fig. 6 - Interaction forces between masonry and confining elements.[10]

As a result, the compression stress used in the calculation of the shear strength of the panel shall be adjusted by adding the effect of this interaction: $\sigma_{0}=\sigma_{0, v}+\sigma_{0, I}$ where:

- $\sigma_{0, v}$ is the stress of compression from the vertical load;

- $\sigma_{0, i}$ is the stress of compression from the effect of the interaction between the panel and confinement elements calculated using the formula

$$
\sigma_{0 . i}=\frac{\Delta N}{A}=V \times \frac{n_{w}}{\alpha \times A}
$$

II. The second effect is the interaction panel-confining elements generate an additional shear resistance capacity by dowel effect of reinforcing bars and by contribution stirrups linking these bars. To calculate the dowel effect of vertical rebars, Bourzat et al.[11] assumes that the crack caused by the shear force is oriented approximately at 45 and that it intersects two stirrups. The paper [11] is a recent development of an old work [12]. 

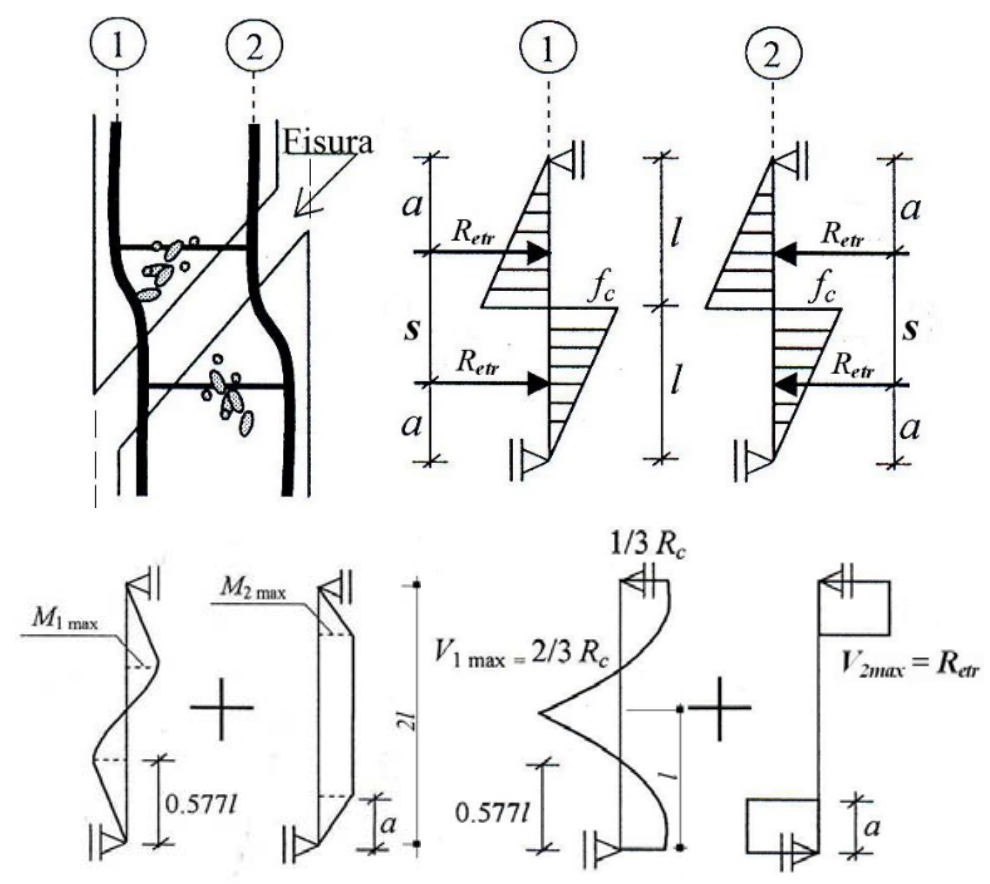

Fig. 7 - Detailed model for dowel action after [11]

The stresses in vertical reinforcements come from:

- The contacts of the reinforcement with the concrete $\left(f_{c x}\right)$, with the maximum value $f_{c}$, considered linearly distributed over a length "l" ;

- The pressure of the stirrups on the vertical bar $\left(R_{s t r}\right)$

Maximum shear force transferred by the dowel effect is when the sum of given stress $\left(f_{c x}\right)$ and stirrups reaction $\left(R_{\text {str }}\right)$ equals the capable moment of vertical bar:

$$
M_{\text {cap }, s}=W_{\text {str }} f_{y s}
$$

Where $W_{\text {str }}$ is the section modulus of stirrups

The maximum shear force transferred by the dowel effect is:

$$
V_{\text {max }, \text { dow. }}=\frac{1}{3} R_{c}+R_{\text {str }}
$$

Equation (6) may be expressed as a fraction of vertical bar resistance $\left(\mathrm{A}_{0, \mathrm{~s}} \times \mathrm{f}_{\mathrm{y}}\right)$ as

$$
\mathrm{V}_{\text {max,dow. }}=\lambda_{\mathrm{c}} \times \mathrm{A}_{0, \mathrm{~s}} \times \mathrm{f}_{\mathrm{y}} .
$$

For current cases, $\lambda_{\mathrm{c}}$ values were calculated for different distances between stirrups retaining for Code minimum values (rounded) given in the table 3 , independent of distances between stirrups. In the current cases, the value $\lambda=0.20$ adopted in CR 6-2006 underestimate the necessary actual reinforcements of vertical confining elements and we decided to replace it with the values given in table 3 .

\begin{tabular}{|c|c|c|c|c|c|c|c|}
\hline \multicolumn{2}{|c|}{ Stirrups } & \multicolumn{6}{|c|}{ Longitudinal rebars in vertical confining elements } \\
\hline \multirow{2}{*}{ Steel } & \multirow{2}{*}{$\Phi$} & \multicolumn{3}{|c|}{ Strength category 1} & \multicolumn{3}{|c|}{ Strength category 2} \\
\hline & & $\Phi 12$ & $\Phi 14$ & $\Phi 16$ & $\Phi 12$ & $\Phi 14$ & $\Phi 16$ \\
\hline \multirow{3}{*}{$\begin{array}{l}\text { Strength } \\
\text { category } 1\end{array}$} & $\Phi 6$ & 0.250 & 0.200 & 0.150 & 0.200 & 0.150 & 0.100 \\
\hline & $\Phi 8$ & 0.400 & 0.350 & 0.250 & 0.300 & 0.250 & 0.200 \\
\hline & $\Phi 10$ & \multicolumn{3}{|c|}{0.400} & \multicolumn{3}{|c|}{0.300} \\
\hline \multirow{3}{*}{$\begin{array}{c}\text { Strength } \\
\text { category } 2\end{array}$} & $\Phi 6$ & \multirow{3}{*}{\multicolumn{3}{|c|}{ Not used }} & 0.250 & 0.200 & 0.150 \\
\hline & $\Phi 8$ & & & & 0.400 & 0.350 & 0.250 \\
\hline & $\Phi 10$ & & & & \multicolumn{3}{|c|}{0.400} \\
\hline
\end{tabular}

$\lambda_{c}$ values adopted in CR 6-2013 


\subsubsection{Confined masonry with horizontal reinforcement $(Z C+A R)$}

Both EC6 and EC8 do not have provisions for the design (calculations and constructive details) of confined masonry walls with horizontal reinforcement if subjected to shear seismic forces. This shortcoming was corrected by the code CR 6-2013 which, in this case, established that the resistance of the wall may be calculated by adding the resistance of the confined masonry wall panel $V_{R d(Z C)}$ (calculated as in 3.2.2.) with the resistance of reinforcements from horizontal joints, $\left(V_{R d 3}\right)$.

$$
V_{R d}(Z C+A R)=V_{R d(Z C)}+V_{R d 3}
$$

$\mathrm{V}_{\mathrm{Rd} 3}$ values are function of the panel dimensions and of the crack length crossed by horizontal rebars.

\section{Conclusions}

Romanian Codes CR 6 -2013 and P100-1/2013 that currently governs the design of masonry structures and non-structural elements are in line with European standards EN 1996 and EN 1998. In the new Romanian Codes have been corrected some of the Eurocodes shortcomings mentioned above namely the formulation of the design rules for confined masonry and the treatment of partial resistance to shear. In text have been added and other provisions from some research results published worldwide. The Codes provisions are accompanied by commentaries and calculation examples that facilitate understanding of the requirements of specific seismic design of masonry structures and the application procedures for verifying their reliability.

\section{References}

[1] ESECMaSE $(2002 \div 2006)$ - Enhanced Safety and Efficient Construction of Masonry Structures in Europe Technical Reports

[2] Ministero dei Lavori Pubblici (2009) Norme Tecniche per le Costruzioni - NTC 2009, Italy

[3] Pluijm, Rob van der (2010), Progress Report from Chairman of CEN/TC 250/SC 6 for the Period up to May 2010 (CEN / TC 250/SC6)

[4] Petrovici, R. Design of Masonry Wall Buildings. Requirements of Codes CR 6 -2013 and P 100-1/2013(I) (in Romanian) AICPS Review nr.4/2012

[5] Ghiocel, D. and al (1985): Civil Building Works (in Romanian), Bucharest: Didactic and Pedagogical Press

[6] Federal Emergency Management Agency (1998) FEMA 306. Evaluation of Earthquake Damaged Concrete and Masonry Wall Buildings. Basic Procedures Manual. Washington DC

[7] Petrovici, R.(2009) Review of the design code CR 6-2006 for masonry buildings (in Romanian) - 4th National Conference on Earthquake Engineering, 18 dec.2009 Tome II (pp.379-386) Bucharest: Conspress Publisher

[8] Petrovici, R.(2015) The design of masonry buildings using European standards adopted in Romania Volume III Reinforced masonry building design (in Romanian). Bucharest: University "I.Mincu" Publisher

[9] Tomazevič, M. (2006), Earthquake Resistant Design of Masonry Buildings, London: Imperial College Press

[10]Zarnic,R., Tomaževič,M (1985) Study of the behaviour of masonry infilled reinforced concrete frames subjected to seismic loading Proc $7^{\text {th }}$ Int.Brick-Masonry Conference vol.2,(pp.1315-1325) Melbourne: Brick Development Research Institute,

[11]Bourzat, A., Goto, T., Miyajima, M.,(2008) Shear Capacity Confined Masonry Walls prediction of Lateral Subjected to Cyclic Loading, Doboku Gakkai Ronbunshuu A No.4,692-704 Vol.64

[12] Priestley, M.J.N. and Bridgeman, D.O (1974).: Seismic resistance of brick masonry walls, Bull. of the New Zealand Nat. Soc. for Earthquake Engrg. 7 (4) pp. 167-187. 6,

[13] SR EN 1996-1-1: 2006 Design of masonry structures

[14] SR EN 1998-1: 2004 Design of structures for earthquake resistance.

[15] CR 6-2013 Code for Design of Masonry Structures.

[15a] CR 6-2006 Code for Design of Masonry Structures.

[16] P 100-1/2013 Code for Seismic Design - Part I- Design provisions for buildings

[16a] P 100-1/2006 Code for Seismic Design - Part I- Design provisions for buildings

[17] NE 036-2014 Code of Practice for the execution and supervising the execution of masonry works 